\title{
Surface structure and properties of poly-(ethylene terephthalate) hydrolyzed by alkali and cutinase
}

\author{
Ilaria Donelli ${ }^{a}$, Giuliano Freddi ${ }^{a, *}$, Vincent A. Nierstrasz ${ }^{b}$, Paola Taddei $^{c}$ \\ a Stazione Sperimentale per la Seta, via Giuseppe Colombo 83, 20133 Milano, Italy \\ ${ }^{\mathrm{b}}$ Department of Textiles, Ghent University, Technologiepark 907, 9052 Gent, Belgium \\ ${ }^{c}$ Dipartimento di Biochimica “G. Moruzzi”, Sezione di Chimica e Propedeutica Biochimica, Università di Bologna, via Belmeloro 8/2, 40126 Bologna, Italy
}

\section{A R T I C L E I N F O}

\section{Article history:}

Received 18 December 2009

Received in revised form

10 May 2010

Accepted 15 June 2010

Available online 22 June 2010

\section{Keywords:}

Poly-(ethylene terephthalate) (PET)

Cutinase

Alkali

FTIR spectroscopy

Water contact angle

\begin{abstract}
A B S T R A C T
This study was aimed at comparatively investigating the hydrolysis of crystalline and amorphous poly(ethylene terephthalate) films by alkali and cutinase. Changes of surface properties were investigated by FTIR spectroscopy (ATR mode). The $A_{1341} / A_{1410}$ and $I_{1120} / I_{1100}$ absorbance ratios, and the full width at half maximum of the carbonyl stretching band $\left(\mathrm{FWHM}_{1715}\right)$ were used to evaluate the polymer crystallinity and its changes upon hydrolysis. The effect of different treatments on chain orientation was evaluated by calculating $\mathrm{R}$ ratios of appropriate bands. The spectroscopic indexes showed that both alkali and enzyme treatments induced structural and conformational rearrangements with a consequent increase in crystallinity in both amorphous and crystalline films. The crystalline PET film was modified more strongly by alkali than by cutinase, while the opposite occurred for the amorphous one. The trend of the water contact angle (WCA) clearly indicates that alkali is more effective than cutinase in enhancing hydrophilicity of PET films and that the effect is stronger on amorphous than on crystalline films. The values of WCA correlate well with the FTIR indexes calculated from the spectra of hydrolyzed crystalline PET films. The mechanism of the surface hydrolysis of PET by alkali and cutinase is discussed.
\end{abstract}

(c) 2010 Elsevier Ltd. All rights reserved.

\section{Introduction}

Polyester [poly-(ethylene terephthalate), PET] fibres are used in a great number of application areas such as apparel, home furnishing and interior textiles, hygiene and medical textiles. Their production accounted for 30.3 million metric tons in 2008, including both staple fibres and filament yarns, representing about $72 \%$ of the entire manmade fibre spinning business [1]. PET textiles have outstanding chemical, physical, and mechanical properties but suffer from some drawbacks due to the intrinsic hydrophobic and inert nature of the constituent polymer. Low moisture regain and poor wettability cause a variety of problems both during manufacturing (e.g. accumulation of static electricity) and consumer use (e.g. clinging to the body, accumulation of fluff and soil).

The treatment of PET textiles with strong alkali (sodium hydroxide, $\mathrm{NaOH}$ ) has been widely investigated and applied at industrial level as a tool to enhance their processing and end use performance (better dyeability and finishing properties, softer and silky handle, improved hydrophilicity and moisture management,

\footnotetext{
* Corresponding author. Tel.: +39 22665990; fax: +39 22362788.

E-mail address: freddi@ssiseta.it (G. Freddi).
}

lower static electricity charge, etc.) [2-6]. Hydroxyl anions are responsible for the hydrolytic scission of ester bonds and removal of small PET monomers/oligomers from the polymeric material. It is widely recognized that the alkaline attack is confined to the PET surfaces exposed to the liquid, because highly ionized compounds like aqueous sodium hydroxide are not allowed diffusing too much into the bulk due to the strongly non-polar environment of PET. A peeling mechanism has been proposed by which alkali attacks PET chains (preferentially from the end groups) and removes hydrolyzed PET material, thus leading to the formation and exposition of new surfaces [4]. This mechanism seems to be confirmed by the progressive weight loss and decrease in size of PET fibres, which are accompanied by the negligible changes in the degree of polymerization and crystallinity, and in the ultimate tensile performance of alkali-treated PET fibres. One of the most peculiar morphological features of alkali-treated PET materials is the presence of pits on the surface, i.e., voids which are thought to play a significant role in surface-related phenomena. Besides being high energy demanding and chemicals consuming, the conventional alkaline treatment is considered quite aggressive towards PET textiles. If not well controlled it may lead to deterioration of the intrinsic mechanical and aesthetic properties of PET, with occurrence of faults and overall reduction of product quality. 
Biocatalysis is emerging as an increasingly attractive tool for the surface hydrolysis and functionalisation of synthetic polymers $[7,8]$. Various cutinases, lipases, and esterases can cleave the ester bond in aliphatic and aromatic polyesters [9-12]. Deacetylation of poly (vinyl acetate) by cutinases has been recently reported [13]. Cutinases are under investigation for the bioprocessing of PET textiles on an industrial scale. Since the catalytic activity of commercially available cutinases is not sufficiently high to fit the requirements of the textile industry, current research efforts aim at discovering more efficient enzymes in terms of thermal stability and catalytic activity by screening new microorganisms or by site-directed mutagenesis of available wild types [11,12,14-19]. Enzymes preferentially attack the amorphous regions of polyesters [20-22]. Chain mobility, which is less restricted in the amorphous regions, is one of the main factors responsible for the biodegradability of polyesters [15]. The enzymatic hydrolysis of PET is expected to result in cleavage of backbone ester bonds and generation of new free hydroxyl and carboxyl groups at the polymer surface, thus leading to increased hydrophilicity of the PET substrate [23].

In a recent study we investigated the chemical and physical changes induced by cutinase on the surface of crystalline and amorphous PET films [24]. Surface hydrophilicity was measured by means of water contact angle (WCA), while surface structural and conformational changes of PET films were monitored by Fourier Transform Infrared spectroscopy (FTIR) in the Attenuated Total Reflectance (ATR) mode. Cutinase displayed higher hydrolytic activity towards amorphous PET. FTIR-ATR allowed highlighting chemical and structural features attributable to the effect of cutinase on the outermost layers of the PET films. Esterification of the free carboxyl groups available at the surface of PET with a fluorescent alkyl bromide (2-(bromomethyl)naphthalene) resulted in higher photoluminescence for the cutinase-hydrolyzed PET film compared to the alkali-treated one, indicating that the enzyme was able to generate higher amounts of free carboxyl groups than alkali [23].

The aim of this study is to comparatively investigate the surface structural changes induced on PET films by alkali and cutinase treatment. A complete spectroscopic characterization of PET films will be presented first. FTIR spectroscopy has proved to be a powerful tool to probe the conformational changes of PET polymers involving either the ethylene glycol moieties, the benzene rings, and the carbonyl groups [25]. Then, surface chemical, structural, and conformational changes of amorphous and crystalline PET films incubated with alkali or cutinase will be discussed with the aim to elucidate details of chemical and biocatalytic modification of PET.

\section{Materials and methods}

\subsection{Materials}

The commercial enzyme formulation containing cutinase from Fusarium solani pisi was obtained from inoTEX Ltd (Dvưr Králové, n.L. Czech Republic). Before use, it was diluted 1:1 with water and dialyzed in cellulose tube (Sigma-Aldrich, cut-off of $12 \mathrm{kDa}$ ) against distilled water to remove low molecular weight additives [24]. The activity of cutinase was tested by means of the Sigma-Aldrich assay for esterase activity (EC 3.1.1.1), using 4-nitrophenyl butyrate as substrate. Analytical grade chemicals (sodium hydroxide, buffer salts, enzyme assay reagents) and the protease Alcalase ${ }^{\circledR} 2.4 \mathrm{~L}$ were purchased from Sigma-Aldrich and used without further purification. Crystalline, biaxially oriented poly-(ethylene terephthalate) (PET) (Fait Plast S.p.A., Italy) and amorphous PET (University of Twente, The Netherlands) films, abbreviated as PET-Cr and PET-Am, respectively, were use as substrate [24].

\subsection{Enzymatic and alkaline treatment of PET films}

The PET films were cut into pieces of $10 \times 1.5 \mathrm{~cm}$, washed with $1 \% \mathrm{w} / \mathrm{v}$ SDS solution for $30 \mathrm{~min}$, at $50-60{ }^{\circ} \mathrm{C}$, and then thoroughly rinsed with distilled water. PET samples were incubated with cutinase in phosphate buffer $50 \mathrm{mM}$, at pH 8.0 into $14 \mathrm{~mL}$ Falcon tubes. The enzyme-to-substrate ratio was $20 \mathrm{U} / \mathrm{mg}$ and the material-to-liquor ratio 1:85. Incubation time and temperature were $120 \mathrm{~min}$ and $40{ }^{\circ} \mathrm{C}$, respectively. The Falcon tubes were closed into the beakers of a Linitest Heraeus apparatus set at $40^{\circ} \mathrm{C}$ and $40 \mathrm{rpm} /$ min rotating speed. Appropriate blank samples without cutinase and treated with heat deactivated cutinase were run under the same experimental conditions. After incubation, the samples were first washed with $1 \% \mathrm{w} / \mathrm{v}$ Sodium dodecyl sulfate (SDS) solution for $30 \mathrm{~min}$ at $50-60^{\circ} \mathrm{C}$, rinsed with distilled water, then incubated in $14 \mathrm{~mL}$ of $10 \mathrm{mM}$ sodium acetate buffer containing $5 \mathrm{mM}$ calcium acetate, $5 \mathrm{mg} / \mathrm{mL}$ Alcalase, at $\mathrm{pH} 7.5$, at $55^{\circ} \mathrm{C}$, for $240 \mathrm{~min}$, and finally rinsed with water and dried at room temperature overnight.

For the alkaline treatment, PET films were immersed in a $1 \mathrm{M}$ $\mathrm{NaOH}$ aqueous solution at $40^{\circ} \mathrm{C}$, for different times, from $30 \mathrm{~min}$ to $24 \mathrm{~h}$, under agitation on a shaking bath (Isco SBH/D, $110 \mathrm{rpm} / \mathrm{min}$ ). Afterwards, membranes were extensively washed with distilled water and dried at room temperature overnight.

\subsection{Fourier transform-infrared spectroscopy (FTIR)}

Measurements were performed on a NEXUS Thermo Nicolet FTIR spectrometer employing an Attenuated Total Reflectance (ATR) accessory mod. Smart Performer. All spectra were obtained with a Ge crystal cell (maximum depth $0.8 \mu \mathrm{m}$ ). Spectra were normalized to the $1410 \mathrm{~cm}^{-1}$ peak before any data processing. Each spectrum reported is the average of at least three spectra measured in different areas of the film. Due to the intrinsic orientation of PET$\mathrm{Cr}$, the spectra were recorded by positioning the samples along one specific direction (conventionally termed MD - machine direction) and perpendicularly to it (conventionally termed TD- transverse direction). The same procedure was utilised also for the nonoriented PET-Am. To evaluate the effect of different treatments on chain orientation, the MD/TD absorbance ratios (R) of specific bands were calculated as follows: $R=A_{\mathrm{MD}} / A_{\mathrm{TD}}$ or $R=I_{\mathrm{MD}} / I_{\mathrm{TD}}$, where $A_{\mathrm{MD}}, A_{\mathrm{TD}}, I_{\mathrm{MD}}$, and $I_{\mathrm{TD}}$ are the absorbance values measured as peak area $(A)$ or peak height $(I)$ in the MD and TD directions, respectively. For a quantitative assessment of the degree of crystallinity, the values of the $A_{1341} / A_{1410}$ and $I_{1120} / I_{1100}$ spectroscopic indexes were calculated on the basis of peak area $(A)$ or peak height $(I)$.

\subsection{Water contact angle (WCA)}

Measurements were performed at room temperature using a FTA188 Contact Angle and Surface Tension Analyzer (First Ten Ångstroms). The analytical protocol used for WCA measurements has been reported elsewhere [24]. Briefly, an average of 8-10 spot measurements were made along the flat surface of each PET film and the WCA values thus obtained were averaged. This approach allowed minimizing the high degree of variability of the surface properties of these films, probably attributable to the industrial processing technology used for their manufacture.

\section{Results}

\subsection{FTIR spectra of untreated PET-Cr and PET-Am films}

Typical FTIR spectra of untreated amorphous (PET-Am) and crystalline (PET-Cr) PET films are shown in Fig. 1. Band wavenumbers and assignments are listed in Table 1. Due to the intrinsic 


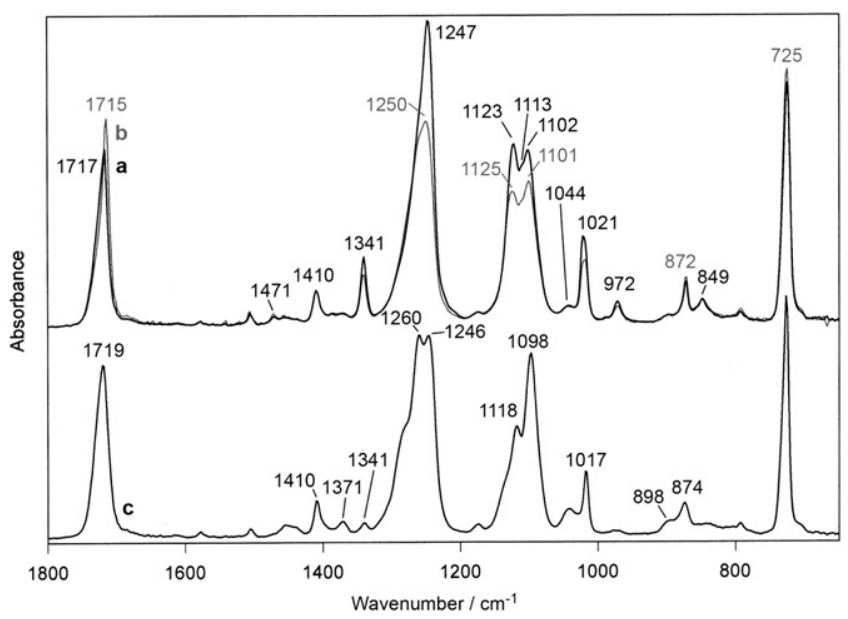

Fig. 1. FTIR spectra of untreated PET-Cr in the MD (a, black) and TD (b, grey) directions and PET-Am in the MD direction (c). Spectra were normalized to the $1410 \mathrm{~cm}^{-1}$ peak before any data processing.

orientation of PET-Cr, the spectra were recorded by positioning the sample along one specific direction, conventionally termed "machine direction" (MD), and along a direction perpendicular to it, conventionally termed "transverse direction" (TD). In fact, as it can be seen in Fig. 1a and b, some PET-Cr bands are more intense in the MD direction $\left(1341,1247,1123,1102\right.$, and $\left.1021 \mathrm{~cm}^{-1}\right)$, others in the TD direction ( 1715 and $872 \mathrm{~cm}^{-1}$ ). The MD/TD intensity ratios $(R)$ were calculated from the spectra and listed in Table 2 . The values of $R$ range from 0.9 to 1.4 . The same approach was followed for the PET-Am film, but the spectra recorded in the two directions are similar because this sample lacks orientation (only the MD spectrum is shown in Fig. 1c). Accordingly, the values of $R$ calculated from the MD and TD spectra fall very close to 1 .

The bands at $1471,1341,1123,972$, and $849 \mathrm{~cm}^{-1}$ are markers of the crystalline structure of PET, while those at 1371, 1044, and $898 \mathrm{~cm}^{-1}$ characterize the amorphous conformation (see Table 1 and references cited therein). In addition, the higher wavenumber component of the strong doublet at about $1120-1100 \mathrm{~cm}^{-1}$ is assigned to crystalline PET, while that at lower wavenumbers to amorphous PET. All crystalline marker bands appear with higher intensity in the spectra of PET-Cr (Fig. 1a and b), while they are sensibly weaker or even absent in the spectrum of PET-Am, which displays stronger amorphous marker bands (Fig. 1c).

For a quantitative assessment of the degree of crystallinity, the values of the spectroscopic indexes $A_{1341} / A_{1410}$ and $I_{1120} / I_{1100}$ were calculated as absorbance ratios and listed in Table 3. PET-Cr is characterized by higher values of the $A_{1341} / A_{1410}$ and $I_{1120} / I_{1100}$ indexes. Table 3 also lists the values of Full Width at Half Maximum of the carbonyl stretching band at $1715 \mathrm{~cm}^{-1}\left(\mathrm{FWHM}_{1715}\right)$. PET-Cr exhibits lower values of FWHM 1715 than PET-Am. Moreover, the value of $\mathrm{FWHM}_{1715}$ is lower in the TD than in the MD direction. No changes of the FWHM 1715 values are observed for PET-Am as a function of the direction.

\subsection{Aging of PET-Am films}

Amorphous PET materials may undergo the so-called physical aging when subjected to water treatment below glass transition temperature $\left(T_{\mathrm{g}}\right)$ [39]. Before treatment with alkali or cutinase, samples of PET-Am were treated with water alone in a temperature range from $25{ }^{\circ} \mathrm{C}$ to $85{ }^{\circ} \mathrm{C}$ (below and beyond $T_{\mathrm{g}}$ ) for $2 \mathrm{~h}$ and then analyzed by FTIR in order to investigate the effect of water treatment on the FTIR marker bands used in this study for the characterization of alkali and cutinase treated films. Fig. 2 shows the FTIR profiles recorded in the range $1450-1000 \mathrm{~cm}^{-1}$ and the trend of the $A_{1341} / A_{1410}$ and $I_{1120} / I_{1100}$ indexes as a function of temperature. No significant changes can be detected for the two indexes below $T_{\mathrm{g}}$, in the range of treatment temperatures used in this study $\left(40-60^{\circ} \mathrm{C}\right)$. On the other hand, at temperatures close to or higher than $T_{\mathrm{g}}$ the spectral changes involving the marker bands are evident and the values of the two indexes change accordingly.

\subsection{FTIR spectra of PET-Cr and PET-Am films treated with alkali}

PET-Cr and PET-Am films were treated with alkali $(\mathrm{NaOH})$ and analyzed by FTIR. The higher resistance of the PET-Cr film under alkaline conditions made it possible to perform alkali treatments from $30 \mathrm{~min}$ up to $24 \mathrm{~h}$ in order to evaluate the trend of surface hydrophilicity (see paragraph 3.5). A weight loss of $<1$ w\% was recorded for PET-Cr films treated with $1 \mathrm{M} \mathrm{NaOH}$ at $40 \mathrm{~min}$. This value is in agreement with previously reported results [4]. A $2 \mathrm{~h}$ treatment was the limit time for the PET-Am film. A weight loss of about $3.6 \mathrm{w} \%$ was recorded after $2 \mathrm{~h}$ of immersion in $1 \mathrm{M} \mathrm{NaOH}$ at $40^{\circ} \mathrm{C}$. Longer times caused extensive film degradation, thus making any further measurement very difficult. To investigate the changes in molecular orientation of PET chains at the surface of the films, all the spectra were acquired along both MD and TD directions, although only MD spectra are reported in the figures.

Upon treatment with alkali the spectra of PET-Cr films showed slight changes involving the bands at 1341, 1123, 1113, 1021, 972, and $849 \mathrm{~cm}^{-1}$, which tend to increase in intensity (Fig. 3b). Interestingly, all these bands are related to the crystalline structure of PET (Table 1 ). Accordingly, the $A_{1341} / A_{1410}$ and $I_{1120} / I_{1100}$ absorbance ratios show a significant increase upon alkali treatment for $30 \mathrm{~min}$, with only minor changes in the subsequent $2-24 \mathrm{~h}$ time interval (Table 3). The intensity of the carbonyl stretching band at $1717 \mathrm{~cm}^{-1}$ decreases and the band sharpens in the TD direction as shown by the lower value of FWHM 1715 which decreases by about $20 \%$ on average (Table 3 ).

The FTIR spectrum of the PET-Am film treated with alkali shows a slight increase in intensity of the crystalline marker band at $1341 \mathrm{~cm}^{-1}$ (Fig. 4b). Changes can also be observed in the doublets at 1260-1246 $\mathrm{cm}^{-1}$ and at $1118-1098 \mathrm{~cm}^{-1}$, where the relative intensity of the higher wavenumber component increases. Accordingly, the values of the $A_{1341} / A_{1410}$ and $I_{1120} / I_{1100}$ absorbance ratios increase (Table 3). The carbonyl stretching band at $1719 \mathrm{~cm}^{-1}$ becomes weaker but, unlike for PET-Cr, the value of $\mathrm{FWHM}_{1715}$ remains unchanged in both MD and TD directions (Table 3 ).

The orientation of the PET chains at the surface of the PET-Cr film seems strongly affected by alkali treatment (Table 2$)$. All the $R$ values increase to various extent, from a minimum of $13 \%\left(R_{1250}\right.$, $\left.R_{1100}\right)$ to a maximum of $43 \%\left(R_{1020}\right)$, with the exception of $R_{1715}$ which decreases. On the other hand, alkali does not seem to affect the orientation of the PET chains at the surface of PET-Am film.

\subsection{FTIR spectra of PET-Cr and PET-Am films treated with cutinase}

PET-Cr and PET-Am films were incubated with cutinase for $2 \mathrm{~h}$ and then analyzed by FTIR. Longer treatment times (up to $24 \mathrm{~h}$ ) do not cause significant improvement of surface hydrophilicity as indicated by WCA values (see next paragraph). No weight loss was detected for both PET-Cr and PET-Am upon cutinase treatment.

The spectral pattern of the PET-Cr film treated with cutinase (Fig. 3c) is closely similar to that of the film treated with alkali (Fig. 3b), but the changes appear with lower intensity, as denoted by the values of $A_{1341} / A_{1410}$ and $I_{1120} / I_{1100}$ absorbance ratios which increase less than with alkali (Table 3 ). Also the intensity and the value of $\mathrm{FWHM}_{1715}$ of the carbonyl stretching band at $1715 \mathrm{~cm}^{-1}$ 
Table 1

Wavenumbers and assignments of the IR bands of PET-Cr and PET-Am.

\begin{tabular}{|c|c|c|c|c|}
\hline$\frac{\text { PET-Cr MD }}{\text { Wavenumbe }}$ & $\underline{\mathrm{PET}-\mathrm{Cr} \text { TD }}$ & PET-Am MD/TD & Assignments & Conformation \\
\hline $1717 \mathrm{~s}$ & $1715 \mathrm{~s}$ & $1719 \mathrm{~s}$ & $\mathrm{C}=\mathrm{O}$ stretching & $\begin{array}{l}\text { 1725: amorphous [26] } \\
\text { 1718: crystalline }[26]\end{array}$ \\
\hline $1578 \mathrm{w}$ & $1578 \mathrm{w}$ & $1578 \mathrm{vw}$ & ring CC stretching [26] & \\
\hline $1506 \mathrm{w}$ & $1506 \mathrm{w}$ & $1505 \mathrm{w}$ & $\begin{array}{l}\text { ring } \mathrm{CH} \text { in-plane bending } \\
\text { ring } \mathrm{CC} \text { stretching }\left(\nu_{19 a}\right)[26-31]\end{array}$ & \\
\hline $1471 \mathrm{w}$ & $1471 \mathrm{w}$ & & $\mathrm{CH}_{2}$ bending $[26-30,32,33]$ & $\begin{array}{l}\text { trans }[26,28-30,32] \\
\text { crystalline }[25,26,34]\end{array}$ \\
\hline $1458 \mathrm{vw}$ & $1458 \mathrm{vw}$ & $1455 \mathrm{w}$ & $\begin{array}{l}\mathrm{CH}_{2} \text { bending }[26-30,32,35] \\
\mathrm{OCH} \text { bending }[28,29]\end{array}$ & $\begin{array}{l}\text { 1456: trans }[35] \\
\text { 1453: gauche }[26,30,33,35], \\
\text { amorphous }[25,27,34]\end{array}$ \\
\hline $1410 \mathrm{~m}$ & $1410 \mathrm{~m}$ & 1409 & $\begin{array}{l}\text { ring } \mathrm{CH} \text { in-plane bending } \\
\text { ring CC stretching }[26,28-30,33] \\
\left(\nu_{13 \mathrm{a}}^{\prime},[31] \nu_{5}+\nu_{16 \mathrm{~b}}[27]\right)\end{array}$ & \\
\hline 1386 vw & $1386 \mathrm{vw}$ & & ring $\mathrm{CH}$ in-plane bending [36] & cristalline [36] \\
\hline $1370 \mathrm{vw}$ & $1370 \mathrm{vw}$ & $1371 \mathrm{w}$ & $\mathrm{CH}_{2}$ wagging $[26,30-32,35]$ & $\begin{array}{l}\text { gauche }[26,30-32,35] \\
\text { amorphous }[25,27,34]\end{array}$ \\
\hline $1341 \mathrm{~m}$ & $1341 \mathrm{~m}$ & $1340 \mathrm{w}$ & $\begin{array}{l}\mathrm{CH}_{2} \text { wagging }[28-32,35] \\
\text { OCH bending }[28,29]\end{array}$ & $\begin{array}{l}\text { 1344: trans }[28-33,35] \\
\text { crystalline }[25,27,34,37] \\
\text { 1338: trans amorphous }[26]\end{array}$ \\
\hline 1247 vs & $1250 \mathrm{~s}$ & $\begin{array}{l}1260 \mathrm{~s} \\
1246 \mathrm{~s}\end{array}$ & $\begin{array}{l}\mathrm{C}(=\mathrm{O})-\mathrm{O} \text { stretching } \\
\text { ring-ester CC stretching } \\
\mathrm{C}=\mathrm{O} \text { in-plane bending }[28-30,33]\end{array}$ & \\
\hline $1174 \mathrm{w}$ & $1174 \mathrm{w}$ & $1174 \mathrm{vw}$ & ring $\mathrm{CH}$ in-plane bending [26] & \\
\hline $1123 \mathrm{~s}$ & $1125 \mathrm{~s}$ & $1118 \mathrm{~m}$ & $\begin{array}{l}\mathrm{O}-\mathrm{CH}_{2} \text { stretching } \\
\text { ring } \mathrm{CC} \text { stretching [27-29,33] } \\
\text { ring } \mathrm{CH} \text { in-plane bending [30] }\end{array}$ & crystalline $[25,27,34,37]$ \\
\hline $1113 \mathrm{sh}$ & $1113 \mathrm{sh}$ & & $\begin{array}{l}\text { ring } \mathrm{CC} \text { stretching } \\
\text { ring } \mathrm{CH} \text { in-plane bending }[28,29]\end{array}$ & crystalline [25] \\
\hline $1102 \mathrm{~s}$ & $1101 \mathrm{~s}$ & $1098 \mathrm{~s}$ & $\mathrm{C}-\mathrm{O}$ stretching $[30,32]$ & $\begin{array}{l}\text { gauche }[26,32] \text { and trans [26] } \\
\text { amorphous }[34,36,37]\end{array}$ \\
\hline $1044 \mathrm{w}$ & $1044 \mathrm{w}$ & $1042 \mathrm{mw}$ & C-O stretching $[26,32]$ & $\begin{array}{l}\text { gauche }[26,30,32,35] \\
\text { amorphous }[34,35,36]\end{array}$ \\
\hline $1021 \mathrm{~m}$ & $1019 \mathrm{~m}$ & $1017 \mathrm{~m}$ & $\begin{array}{l}\text { ring CCC bending } \\
\text { ring CC stretching } \\
\text { ring } \mathrm{CH} \text { in-plane bending }\left(\nu_{18 \mathrm{a}}\right)[26-30,32,37]\end{array}$ & $\begin{array}{l}\text { 1018: gauche }[26,38] \\
\text { 1020: trans amorphous }[26,38] \\
\text { 1024: trans crystalline }[26,38]\end{array}$ \\
\hline $972 w$ & $972 \mathrm{w}$ & $978 \mathrm{vw}$ & $\begin{array}{l}\mathrm{O}-\mathrm{CH}_{2} \text { stretching } \\
\mathrm{C}(=\mathrm{O})-\mathrm{O} \text { stretching }[26,28,29,33]\end{array}$ & $\begin{array}{l}\text { 972: trans }[26,28-30,35,37] \\
\text { crystalline }[25,27,34] \\
\text { 979: trans amorphous }[26]\end{array}$ \\
\hline $898 \mathrm{vw}$ & $898 \mathrm{vw}$ & $896 \mathrm{w}$ & $\mathrm{CH}_{2}$ rocking $[26,30,32]$ & $\begin{array}{l}\text { gauche }[26,30,32,37] \\
\text { amorphous }[25,27,34]\end{array}$ \\
\hline $872 \mathrm{~m}$ & $872 \mathrm{~m}$ & $874 \mathrm{~m}$ & $\begin{array}{l}\text { ring } \mathrm{CH} \text { out-of-plane bending } \\
\text { ring-ester } \mathrm{C}-\mathrm{C} \text { out-of-plane bending } \\
\mathrm{C}=\mathrm{O} \text { out-of-plane bending } \\
\text { ring torsion }\left(\nu_{17 \mathrm{~b}}\right)[26-30,35-37]\end{array}$ & \\
\hline $849 \mathrm{~m}$ & $849 \mathrm{~m}$ & & $\begin{array}{l}\text { ring } \mathrm{CC} \text { stretching } \\
\text { ring-ester } \mathrm{CC} \text { stretching } \\
\mathrm{CCH} \text { bending } \\
\mathrm{COC} \text { bending } \\
\mathrm{C}(=\mathrm{O})-\mathrm{O} \text { stretching } \\
\mathrm{C}=\mathrm{O} \text { in plane bending }[28,29] \\
\mathrm{CH}_{2} \text { rocking }[26,27,32,33]\end{array}$ & $\begin{array}{l}\text { trans }[26,30,32,37] \\
\text { crystalline }[25,27,34]\end{array}$ \\
\hline $793 w$ & $793 w$ & $793 w$ & $\begin{array}{l}\text { ring } \mathrm{CH} \text { out-of-plane bending [30] } \\
\mathrm{C}=\mathrm{O} \text { rocking }+\mathrm{CCO} \text { bending }[31]\end{array}$ & \\
\hline $725 \mathrm{~s}$ & $725 \mathrm{~s}$ & $726 \mathrm{~s}$ & $\begin{array}{l}\mathrm{C}=\mathrm{O} \text { out-of-plane bending } \\
\text { ring torsion } \\
\text { ring } \mathrm{CH} \text { out-of-plane bending }\left(\nu_{11}\right)[26-30,37]\end{array}$ & \\
\hline
\end{tabular}

$\mathrm{s}=$ strong; $\mathrm{m}=$ medium $; \mathrm{w}=$ weak $\mathrm{vw}=$ very weak; $\mathrm{sh}=$ shoulder. 
Table 2

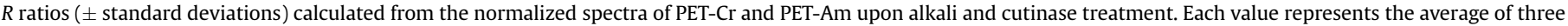
spectra recorded along the MD and TD directions.

\begin{tabular}{|c|c|c|c|c|c|c|c|c|}
\hline Sample & & $R_{1715}$ & $R_{1341}$ & $R_{1250}$ & $R_{1120}$ & $R_{1100}$ & $R_{1020}$ & $R_{875}$ \\
\hline \multirow[t]{6}{*}{ PET-Cr } & Control $^{\mathrm{a}}$ & $0.90 \pm 0.12$ & $1.30 \pm 0.08$ & $1.21 \pm 0.10$ & $1.40 \pm 0.20$ & $1.30 \pm 0.20$ & $1.40 \pm 0.20$ & $0.88 \pm 0.09$ \\
\hline & $\mathrm{NaOH} 30 \mathrm{~min}$ & $0.84 \pm 0.04$ & $1.52 \pm 0.07$ & $1.30 \pm 0.09$ & $1.57 \pm 0.14$ & $1.36 \pm 0.13$ & $1.76 \pm 0.13$ & $0.94 \pm 0.07$ \\
\hline & $\mathrm{NaOH} 2 \mathrm{~h}$ & $0.80 \pm 0.09$ & $1.53 \pm 0.13$ & $1.30 \pm 0.20$ & $1.70 \pm 0.40$ & $1.40 \pm 0.40$ & $1.90 \pm 0.60$ & $1.00 \pm 0.30$ \\
\hline & $\mathrm{NaOH} 6 \mathrm{~h}$ & $0.81 \pm 0.03$ & $1.58 \pm 0.08$ & $1.37 \pm 0.06$ & $1.70 \pm 0.10$ & $1.47 \pm 0.08$ & $2.00 \pm 0.10$ & $1.04 \pm 0.03$ \\
\hline & $\mathrm{NaOH} 24 \mathrm{~h}$ & $0.83 \pm 0.03$ & $1.53 \pm 0.09$ & $1.31 \pm 0.13$ & $1.60 \pm 0.20$ & $1.40 \pm 0.20$ & $1.80 \pm 0.30$ & $1.00 \pm 0.20$ \\
\hline & Cutinase $2 \mathrm{~h}$ & $0.84 \pm 0.13$ & $1.40 \pm 0.20$ & $1.27 \pm 0.14$ & $1.58 \pm 0.12$ & $1.41 \pm 0.12$ & $1.70 \pm 0.30$ & $1.10 \pm 0.14$ \\
\hline \multirow[t]{3}{*}{ PET-Am } & Control $^{\mathrm{a}}$ & $0.98 \pm 0.06$ & $1.10 \pm 0.20$ & $1.01 \pm 0.02$ & $1.04 \pm 0.10$ & $1.03 \pm 0.08$ & $1.04 \pm 0.10$ & $1.01 \pm 0.11$ \\
\hline & $\mathrm{NaOH} 2 \mathrm{~h}$ & $0.96 \pm 0.09$ & $1.05 \pm 0.12$ & $0.98 \pm 0.05$ & $0.97 \pm 0.06$ & $0.99 \pm 0.06$ & $1.00 \pm 0.05$ & $0.97 \pm 0.07$ \\
\hline & Cutinase $2 \mathrm{~h}$ & $1.14 \pm 0.11$ & $0.95 \pm 0.05$ & $1.00 \pm 0.03$ & $0.94 \pm 0.06$ & $0.96 \pm 0.05$ & $0.93 \pm 0.07$ & $0.89 \pm 0.10$ \\
\hline
\end{tabular}

${ }^{\text {a }}$ Control samples are PET films treated with water or buffer alone under the same conditions of temperature and time of alkali and cutinase treated PET film, respectively.

decrease upon cutinase treatment, but less than after alkali treatment. The values of the $R$ ratios follow the same trend observed for alkali treated films (Table 2).

The PET-Am film appears more strongly modified by cutinase than by alkali, as indicated by the significantly lower intensity of the bands at 1246 and $1719 \mathrm{~cm}^{-1}$ (Fig. 3c). Accordingly, the values of $A_{1341} / A_{1410}$ and $I_{1120} / I_{1100}$ absorbance ratios are higher than those calculated for the sample treated with alkali (Table 3 ). No changes can be observed in the value of FWHM $_{1715}$ of the carbonyl stretching band (Table 3 ). Also the values of the $\mathrm{R}$ ratios sensitive to PET chain orientation remain unchanged (Table 2 ).

\subsection{WCA measurements of alkali and cutinase treated PET films}

The results of WCA measurements carried out on PET films treated with alkali and with cutinase are plotted in the graph of Fig. 4.

Both treatments result in a net increase of surface hydrophilicity of PET films. Alkali is more effective than cutinase in enhancing the hydrophilicity of PET films, judging from the comparatively lower WCA values attained. The effect of both alkali and cutinase is stronger on PET-Am than on PET-Cr films, in good agreement with previously reported results [20-22]. The size of the error bars shows that alkali treated films display a higher extent of variability of the WCA values measured along the surface of each individual film [24]. Interestingly, both $\mathrm{NaOH}$ and cutinase lead to a levelling of the WCA values which do not change too much for treatment times longer than $2 \mathrm{~h}$. These trends well agree with previous results reported for PET materials treated with $\mathrm{NaOH}$ [3] or cutinase [11].

Table 3

Values of the spectroscopic indexes ( \pm standard deviations) obtained from the spectra of PET-Cr and PET-Am. Each value represents the average of three spectra.

\begin{tabular}{|c|c|c|c|c|c|}
\hline \multirow[t]{2}{*}{ Samples } & & \multicolumn{2}{|c|}{$\mathrm{FWHM}_{1715}\left(\mathrm{~cm}^{-1}\right)$} & \multirow[t]{2}{*}{$A_{1341} / A_{1410}{ }^{\mathrm{a}}$} & \multirow[t]{2}{*}{$I_{1120} / I_{1100}{ }^{\mathrm{a}}$} \\
\hline & & MD direction & TD direction & & \\
\hline \multirow[t]{6}{*}{ PET-Cr } & Control $^{\mathrm{b}}$ & $18.6 \pm 0.9$ & $14.7 \pm 0.8$ & $1.87 \pm 0.05$ & $1.03 \pm 0.02$ \\
\hline & $\mathrm{NaOH} 30 \mathrm{~min}$ & $19.4 \pm 0.6$ & $12.0 \pm 0.2$ & $2.19 \pm 0.09$ & $1.13 \pm 0.01$ \\
\hline & $\mathrm{NaOH} 2 \mathrm{~h}$ & $19.8 \pm 0.3$ & $11.4 \pm 0.8$ & $2.34 \pm 0.08$ & $1.15 \pm 0.01$ \\
\hline & $\mathrm{NaOH} 6 \mathrm{~h}$ & $19.6 \pm 0.4$ & $11.8 \pm 0.1$ & $2.39 \pm 0.09$ & $1.16 \pm 0.01$ \\
\hline & $\mathrm{NaOH} 24 \mathrm{~h}$ & $19.7 \pm 0.4$ & $11.7 \pm 0.2$ & $2.22 \pm 0.09$ & $1.16 \pm 0.01$ \\
\hline & Cutinase $2 \mathrm{~h}$ & $18.8 \pm 0.3$ & $13.7 \pm 0.4$ & $2.07 \pm 0.11$ & $1.08 \pm 0.01$ \\
\hline \multirow[t]{3}{*}{ PET-Am } & Control $^{\mathrm{b}}$ & $22.1 \pm 0.2$ & $22.0 \pm 0.2$ & $0.21 \pm 0.02$ & $0.59 \pm 0.01$ \\
\hline & $\mathrm{NaOH} 2 \mathrm{~h}$ & $22.1 \pm 0.1$ & $22.1 \pm 0.1$ & $0.31 \pm 0.03$ & $0.63 \pm 0.01$ \\
\hline & Cutinase $2 \mathrm{~h}$ & $21.8 \pm 0.1$ & $22.2 \pm 0.2$ & $0.37 \pm 0.06$ & $0.66 \pm 0.02$ \\
\hline
\end{tabular}

\footnotetext{
a Absorbance ratios calculated from MD spectra.

b Control samples are PET films treated with water or buffer alone under the same conditions of temperature and time of alkali and cutinase treated PET film, respectively.
}

\section{Discussion}

The structure of PET is characterized by the presence of trans and gauche rotational conformers of the ethylene glycol moiety. Both types of conformers are present in the amorphous phase, but only the trans conformer is present in the crystalline phase. In fact, the crystalline markers bands at 1471, 1341, 1123, 972, and $849 \mathrm{~cm}^{-1}$ arise from vibrations of the ethylene glycol moiety in the trans conformation, while the amorphous ones at 1371, 1044, and $898 \mathrm{~cm}^{-1}$ from the gauche conformation (Table 1). Untreated amorphous and crystalline PET films are well characterized by their spectral pattern (Fig. 1). The crystalline marker bands appear with stronger intensity in the spectrum of PET-Cr. Moreover, the spectrum of PET-Cr shows a shoulder at about $1113 \mathrm{~cm}^{-1}$, attributed to crystalline PET, which is absent in the spectrum of PET-Am.
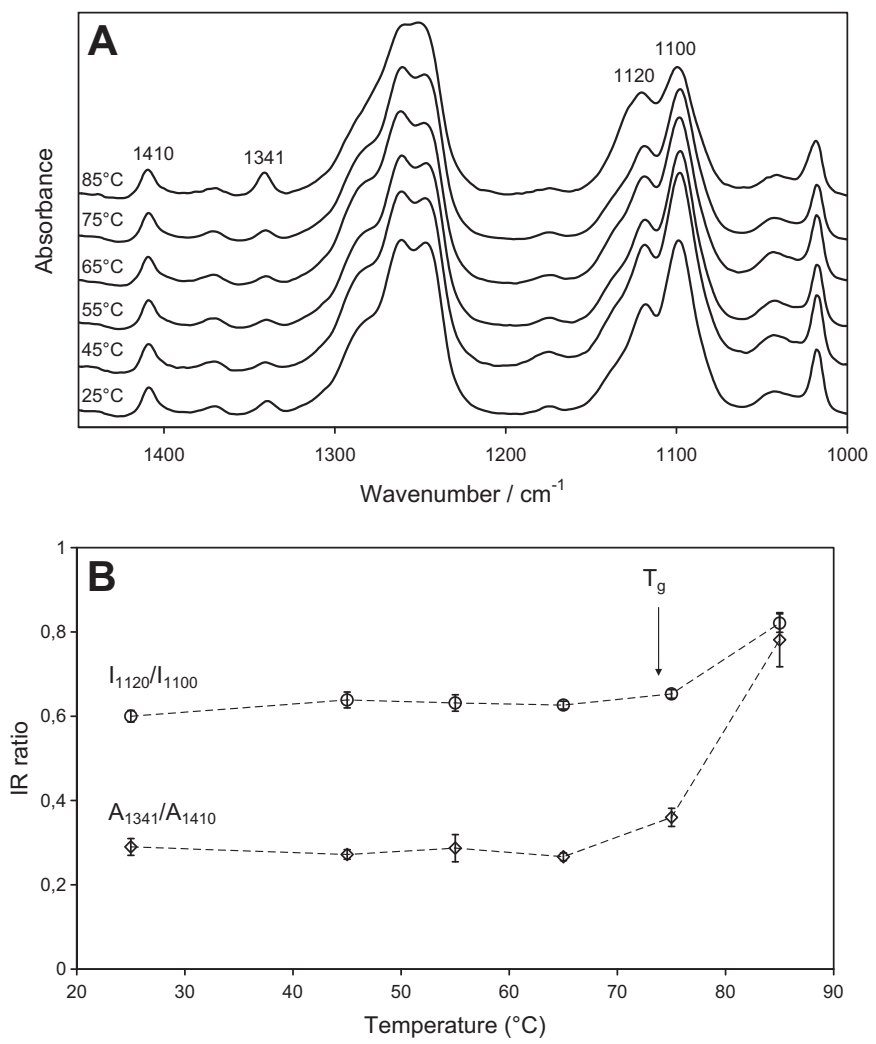

Fig. 2. [A] FTIR spectra of PET-Am films treated with water in the $25-85^{\circ} \mathrm{C}$ temperature range. Spectra were normalized to the $1410 \mathrm{~cm}^{-1}$ peak before any data processing. [B] Behaviour of the $A_{1341} / A_{1410}$ and $I_{1120} / I_{1100}$ FTIR indexes as a function of temperature. 


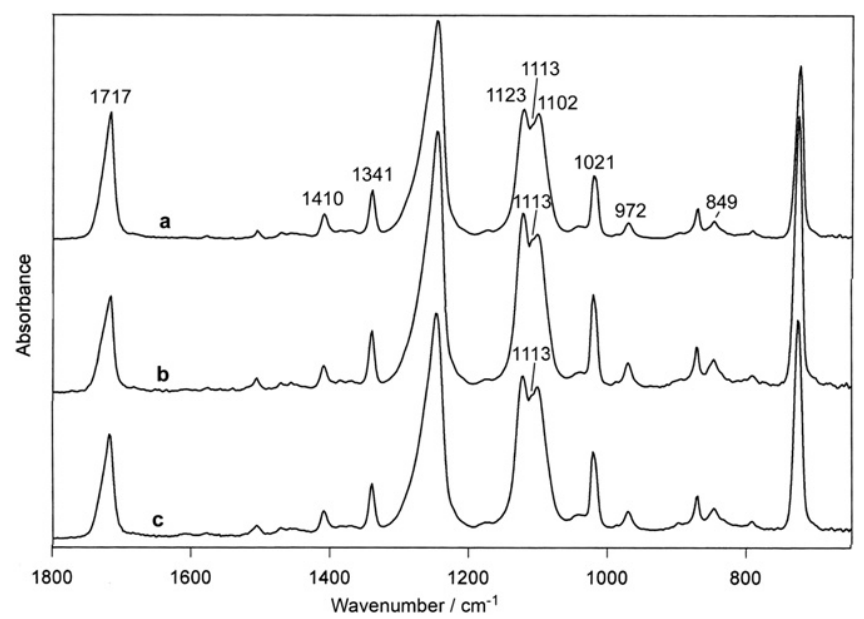

Fig. 3. FTIR spectra (MD direction) of PET-Cr untreated (a), and after treatment with alkali (b) or cutinase (c) for $2 \mathrm{~h}$. Spectra were normalized to the $1410 \mathrm{~cm}^{-1}$ peak before any data processing.

The position of benzene ring vibrations is a further indication of the conformational order of PET-Cr. In particular, the component of the ring bending mode at $1021 \mathrm{~cm}^{-1}$, which has been associated with a more ordered environment of PET chains [26], appears with stronger intensity in the spectrum of PET-Cr, while the component at $1017 \mathrm{~cm}^{-1}$, attributed to the gauche conformation [38], is present in the spectrum of PET-Am. Another ring bending vibration weakens and shifts from $872 \mathrm{~cm}^{-1}$ in PET-Cr to $874 \mathrm{~cm}^{-1}$ in PETAm. This behaviour is not surprising because Cole et al. [26] have observed that the glycol group affects ring vibrations through the interaction of the carbonyl groups with the $\pi$ electrons of the benzene ring.

The carbonyl stretching band appears to be sensitive not only to the crystalline/amorphous state of PET, but also to the orientation of PET chains. In fact, going from amorphous to crystalline PET film, this band shifts to lower wavenumbers, from $1719 \mathrm{~cm}^{-1}$ in PET-Am to $1717 \mathrm{~cm}^{-1}$ and $1715 \mathrm{~cm}^{-1}$ in the MD and TD spectra of PET-Cr, respectively (Fig. 1). Also the value of $\mathrm{FWHM}_{1715}$ decreases from $22.1 \mathrm{~cm}^{-1}$ of PET-Am to $18.6 \mathrm{~cm}^{-1}$ (MD spectrum) and $14.7 \mathrm{~cm}^{-1}$ (TD spectrum) of PET-Cr (Table 3). Sharpening and shifting to lower wavenumbers of the carbonyl band has been reported by Cole et al. [26] for PET samples with crystallinity ranging from $5 \%$ to $28 \%$. This

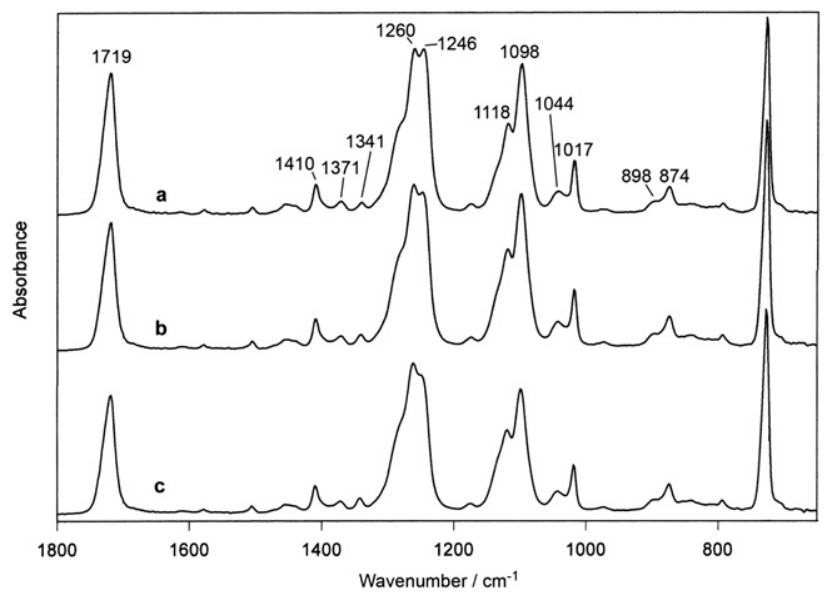

Fig. 4. FTIR spectra (MD direction) of PET-Am untreated (a), and after treatment with alkali (b) or cutinase (c) for $2 \mathrm{~h}$. Spectra were normalized to the $1410 \mathrm{~cm}^{-1}$ peak before any data processing. behaviour is attributed to a more ordered structure imparted on crystalline PET by the coplanarity between the carbonyl groups and the benzene rings.

Although not conformationally sensitive, the strong absorption falling at about $1250 \mathrm{~cm}^{-1}$ is useful for the identification of the structural state of PET. In fact, a couple of bands with maxima at $1260 \mathrm{~cm}^{-1}$ and $1246 \mathrm{~cm}^{-1}$ with closely similar intensity characterizes the amorphous PET, while a single intense band at $1247 \mathrm{~cm}^{-1}$ is present in crystalline PET. All these observations, as well as the values of the spectroscopic indexes $A_{1341} / A_{1410}$ and $I_{1120} /$ $I_{1100}$ reported in Table 3 , confirm the higher crystallinity of PET-Cr as compared to PET-Am, in good agreement with the crystal content determined by DSC analysis (about 35\% and $10 \%$ for PET-Cr and PET-Am, respectively).

Actually, the PET-Cr film is oriented, as denoted by the different intensity of some bands in the MD and TD spectra (Fig. 1) and by the values of the $R$ ratios (Table 2). Although MD and TD spectra were not recorded under the polarized light, they can be used to obtain information on chain orientation. The $\mathrm{R}$ ratios calculated for the bands at $1341,1250,1120,1100$, and $1020 \mathrm{~cm}^{-1}$ are greater than one, in agreement with the MD/TD dichroic ratios reported by Cole et al. [26]. These bands show parallel dichroism: their transition moments are more or less parallel to the polymer chain axis, so MD/TD ratios greater than one correspond to predominant MD orientation. On the other hand, the carbonyl band at $1715 \mathrm{~cm}^{-1}$ and the bending mode of benzene ring at $872 \mathrm{~cm}^{-1}$ are weaker in the MD than in the TD spectrum, thus resulting in $R$ values lower than one, in agreement with the dichroic ratios reported by Cole et al. [26]. These bands show perpendicular dichroism: their transition moments are more or less perpendicular to the polymer chain axis, so MD/TD ratios lower than one correspond to predominant TD orientation. A dichroic ratio of 0.71 , based on the total band area, has been reported for the carbonyl band at $1715 \mathrm{~cm}^{-1}$. However, a spectral subtraction procedure has suggested the presence of two components for this band: one at $1734 \mathrm{~cm}^{-1}$ with a dichroic ratio of 0.52 and one at $1720 \mathrm{~cm}^{-1}$ with a dichroic ratio of 0.81 [26]. These data could also explain the previously observed sharpening and shifting of the carbonyl band going from MD to TD spectra of PET-Cr (Fig. 1).

The treatment with alkali or with cutinase induces a decrease in intensity of the carbonyl stretching band in both PET-Cr and PET-Am, confirming the involvement of the ester carbonyl in the chemical or biocatalytic attack. An analogous trend was observed by Dadsetan et al. [37] in $\mathrm{CO}_{2}$ laser irradiated films. At the same time, the marker bands attributed to the crystalline conformation of PET chains strengthen, suggesting an increase in crystallinity. The significant changes of the $\mathrm{R}$ ratios (Table 2) and of the values of $\mathrm{FWHM}_{1715}$ (Table 3) of PET-Cr as a function of alkali or cutinase treatment seem to suggest that the increase of the degree of surface order may be a consequence of a local structural rearrangement of PET chain segments taking place after hydrolysis. Chain shortening as a consequence of the hydrolytic attack can also contribute to enhance surface crystallinity because better organized crystallites can develop from shorter polymeric chain segments. The increase of surface crystallinity is common to both crystalline and amorphous films treated with alkali or cutinase, but it is more evident for PET-Am films, as confirmed by the values of the spectroscopic index $A_{1341} / A_{1410}$ which increased by $48 \%$ and $76 \%$ upon treatment with alkali and cutinase, respectively. The same index increased only by $25 \%$ (alkali) and $11 \%$ (cutinase) in PET-Cr. These results show that: (i) the more amorphous the PET substrate the stronger the intensity of the hydrolytic attack of both alkali and cutinase, and (ii) cutinase is more active than alkali towards PET-Am, while the reverse occurs for PET-Cr.

With reference to the different effect of alkali and cutinase on the two PET substrates in terms of extent of surface structural modification, the lower activity of cutinase on crystalline PET can be 
attributed to steric hindrance. PET chain segments blocked within a rigid crystalline texture are endowed with lower mobility and are expected to be less accessible for the catalytic site of the enzyme. The different mechanism by which alkali and cutinase hydrolyze PET can probably explain the higher degree of surface order and crystallinity achieved by PET-Am films treated with cutinase. Alkali preferentially attacks the surface of PET by hydrolyzing ester bonds from the chain ends, thus shortening chains and removing hydrolyzed PET material by the peeling mechanism [4]. Depending on treatment conditions, variable extents of weight loss are usually recorded and the typical pitted aspect can be observed on the surface of PET upon alkaline treatment. On the other hand, cutinase and other lypolytic enzymes are capable to hydrolyze the PET chains via the endo mechanism [23]. Usually, no significant weight change is observed and the surface morphology is not affected at the microscopic level. The different extent of surface degradation, as well as the different properties of the chain segments left by cutinase and alkali treatment at the surface of PET, namely chain length and mobility of the chain segments, might have influenced the ability of PET chains to locally rearrange and crystallize. Caparanga et al. [40] have recently reported that PET incubated with a $\mathrm{NaOH}$ solution of a non ionic surfactant causes a decrease of crystallinity. Further insights into this subject are needed.

The degree of crystallinity of the samples prepared in this study was determined also by DSC analyses but no changes were detected as a function of the treatment conditions (data not shown). This confirms previous observations that alkali or cutinase treatments change the surface properties of PET films while leaving the bulk properties unchanged $[4,23]$, or inducing only very small changes [22]. On the other hand, the trend of the WCA values shown in Fig. 5 A clearly indicates that both alkali and cutinase result in a net increase of surface hydrophilicity of PET films. Alkali is more effective than cutinase in enhancing the hydrophilicity of PET films and the effect is stronger on PET-Am than on PET-Cr, in good agreement with previously reported results [23]. It is interesting to note that the WCA values of PET-Cr films treated with alkali drop sharply at $30 \mathrm{~min}$ and then remain almost constant until $24 \mathrm{~h}$. The same behaviour was observed for nearly all the spectroscopic markers reported in Tables 2 and 3. Despite the relatively mild conditions of the alkali treatment $\left(40{ }^{\circ} \mathrm{C}\right.$, the same used for cutinase), the WCA results here reported are in good agreement with previous ones indicating a tendency of the WCA values to level off [3]. The constancy of WCA values of surface hydrolyzed PET films with respect to the time of alkali treatment is probably related to the peeling mechanism of the alkaline hydrolysis, which leads to surface cleaning, to exposition of new surfaces, and to increase of surface roughness and porosity. Thus, it can be suggested that once the most external layers of PET have been peeled off, further alkaline hydrolysis of the newly exposed PET surfaces does not modify the surface properties to such an extent to be monitored by WCA, as well as by FTIR measurements.

Levelling of WCA values, or even a slight recovery of surface hydrophobicity above $2 \mathrm{~h}$ treatment was observed upon incubation with cutinase (Fig. 5B). Alisch-Mark et al. [11] reported a similar behaviour for cutinase-treated PET fibres, which showed lower K/S values (i.e., less ability to absorb the Reactive Red 2 dye, corresponding to a lower degree of hydrophilicity) for longer treatment times with Fusarium solani f. sp. pisi cutinase. This behaviour was attributed to a peeling effect analogously to what happens with alkali. However, in view of the different mechanism of the hydrolytic attack between alkali [4] and cutinase [23], the hypothesis of the peeling mechanism for the enzymatic hydrolysis of PET must be supported by further experimental evidences.

The higher wettability of PET surfaces hydrolyzed by alkali or cutinase can be due to a number of factors, namely chemical
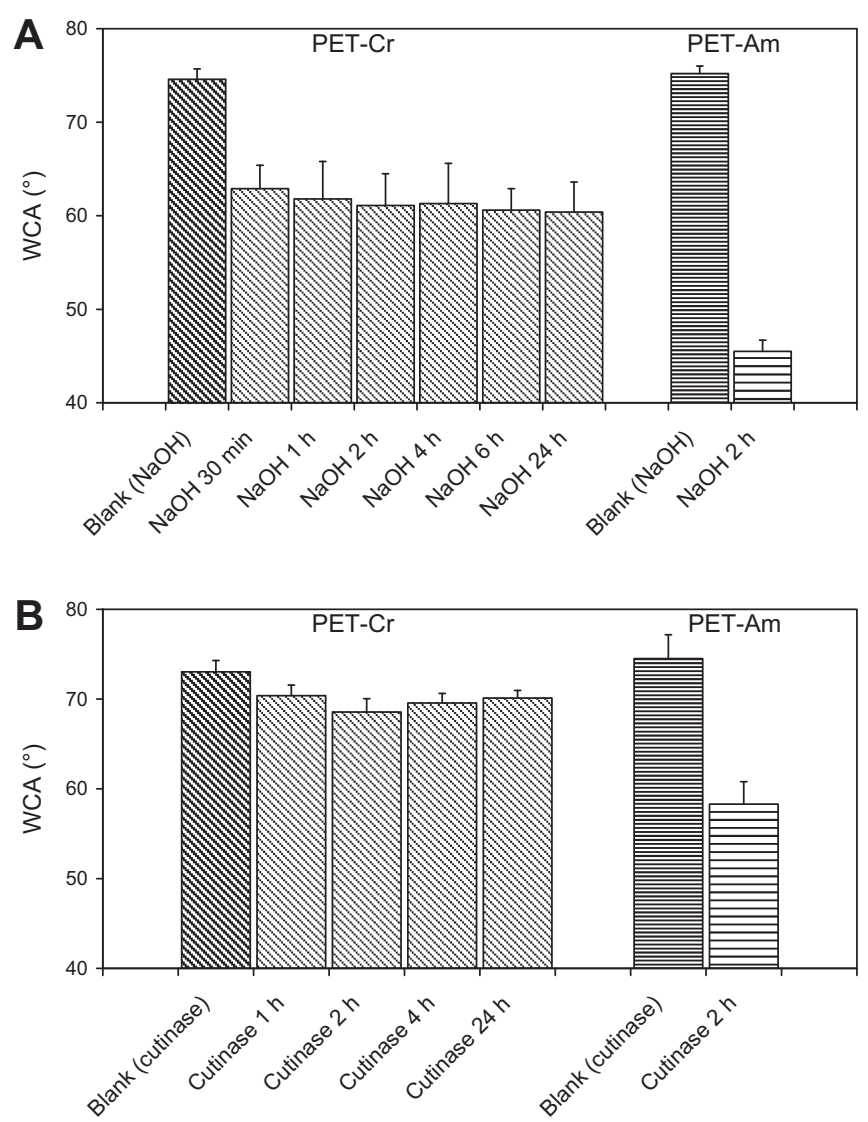

Fig. 5. WCA values of PET-Cr and PET-Am films subjected to alkali $[A]$ or cutinase $[B]$ treatment. The samples marked "Blank $(\mathrm{NaOH})$ " represent PET-Cr or PET-Am films treated with buffer alone, without alkali. The samples marked "Blank (cutinase)" represent films subjected to treatment with heat deactivated cutinase.

(increased amount of free hydroxyl/carboxyl groups), physical (improved accessibility of hydrophilic groups on the newly exposed surfaces), and morphological (increase of surface roughness and porosity). In our previous study [24], untreated, alkali, and cutinase-hydrolyzed PET films were alkylated with the fluorescent alkyl bromide 2-(bromo-methyl)naphthalene (BrNP), a compound which specifically binds the free carboxylic groups of PET. After alkylation with BrNP, untreated and alkali treated PET films displayed closely similar levels of fluorescence emission, which is most likely a consequence of the fact that the alkaline treatment did not induce any detectable increase of the free carboxylic groups at the surface of PET. On the other hand, the photoluminescence of the PET film treated with cutinase was higher, suggesting that a larger number of free carboxylic groups was available at the PET surface. Thus, both alkali and cutinase are able to modify the surface of PET but the net increase of hydrophilicity accounts for the contribution of different factors. Physical and morphological factors (higher surface roughness and porosity) are likely to play the major role in enhancing the surface hydrophilicity of alkali treated PET. On the other hand, chemical factors (larger number of free hydrophilic groups) prevail over the morphological and physical ones in the case of cutinase and drive the surface properties of PET towards a more hydrophilic character.

Despite the different mechanism by which alkali and cutinase modify the surface properties of PET (exo- and endo-cleavage for alkali and cutinase, respectively), the plots of Fig. 6 show that the values of WCA correlate quite well with the FTIR indexes calculated from the spectra of hydrolyzed PET films. More interestingly, the 

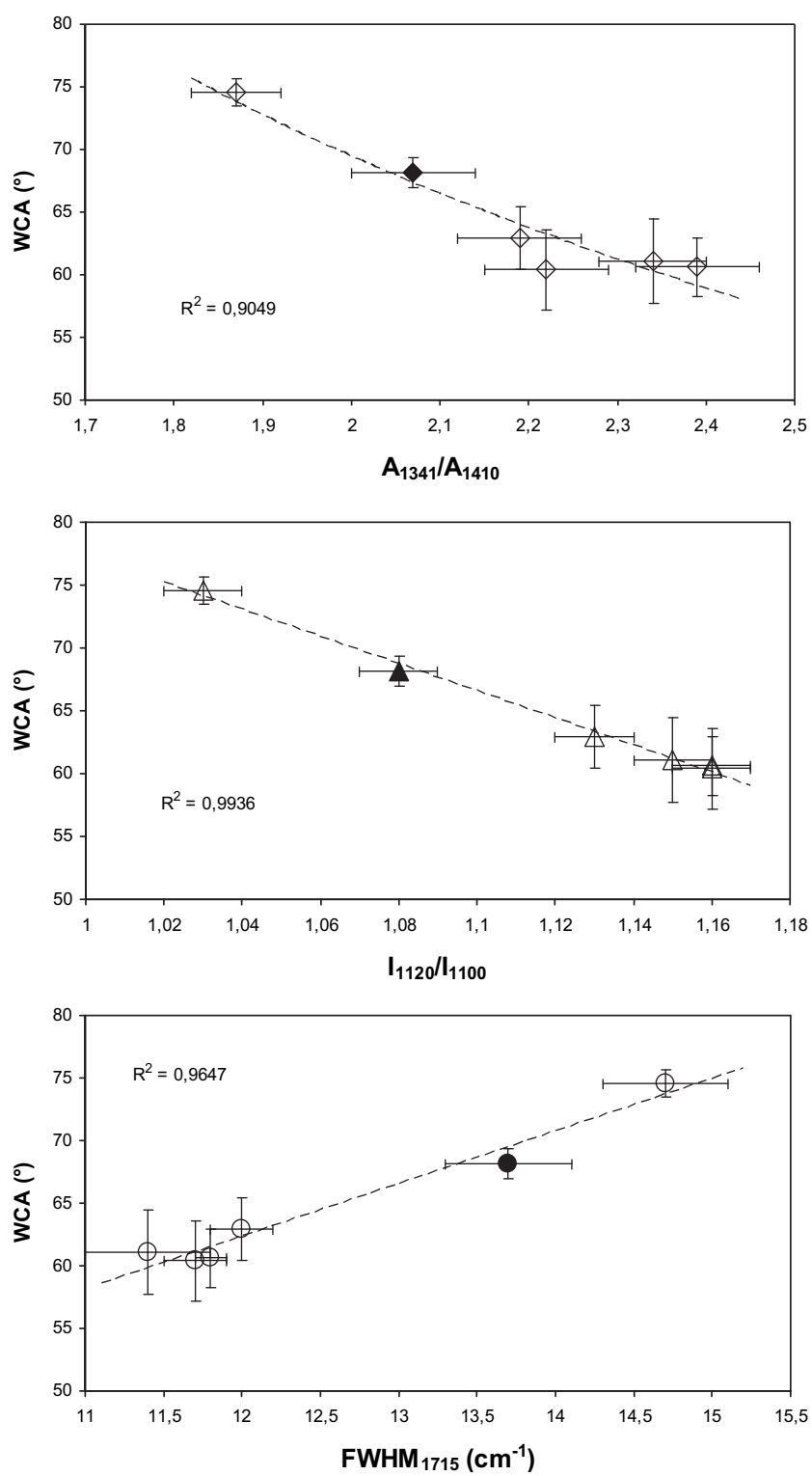

Fig. 6. Correlation between the values of WCA and FTIR indexes calculated from the spectra of hydrolyzed PET-Cr films. The FTIR indexes were obtained from the MD spectra with the exception of $\mathrm{FWHM}_{1715}$ which was calculated from the TD spectra. Full symbol refers to the sample treated with cutinase.

values of the PET film treated with cutinase fit the same regression curves established on the basis of PET films treated with alkali. The significance of this relation cannot be fully explained on the basis of current knowledge of the chemical, physical, and mechanistic aspects of the surface hydrolysis of PET. Further studies are needed to elucidate these topics that might probably have a spin-off for polymer and textile technology.

\section{Conclusions}

In this study, the hydrolytic activity of alkali and cutinase toward crystalline and amorphous PET films was systematically investigated by FTIR measurements. Both alkali and cutinase hydrolyze the chains at the surface of PET, but the mechanism is different.

The FTIR analysis of PET membranes before and after hydrolysis allowed to highlight chemical and structural features involving the outermost layers of the PET polymer. The spectroscopic indexes showed that both alkali and cutinase treatments induced structural and conformational rearrangements with a consequent increase in crystallinity in both crystalline and amorphous PET films. Crystalline films were modified by alkali more strongly than by cutinase while the opposite behaviour was observed for the amorphous ones.

The trend of the WCA values indicates that alkali is more effective than cutinase in enhancing the hydrophilicity of PET films and the effect is stronger on amorphous than crystalline PET. The values of WCA correlate quite well with the FTIR indexes calculated from the spectra of hydrolyzed PET films. Although the significance of this correlation has to be further proved by widening the range of PET substrates and treatment conditions, the results reported in this study indicate that the mechanism of the surface modification of PET by alkali or cutinase is still far from being fully understood and that the application of FTIR, in combination with other conventional or more sophisticated analytical tools, may bring new insights into the kinetics and mechanism of the surface modification of PET. Fundamental knowledge in this field may not only contribute to the development of bioprocesses for polyester substrates, but also address the genetic engineering of enzymes with enhanced hydrolyzing activity with respect to the native ones.

\section{Acknowledgements}

Authors gratefully acknowledge the support of COST Action 868 "Biotechnical Functionalisation of Renewable Polymeric Materials". Vincent A. Nierstrasz acknowledges the support of the European Commission (Marie-Curie grant, People FP7), Grant Agreement Number PIEF-GA-2008-219665. G. Freddi and I. Donelli acknowledge the financial support of the Region of Lombardy (Italy), Grant Agreement ID-4052-2007, Biotex Project.

\section{References}

[1] Oerlikon Textile GmbH \& Co. KG (Germany). The Fiber Year 2008/09. A World Survey on Textile and Nonwovens Industry. Issue 9, May 2009 (www. oerlikontextile.com).

[2] Ellison MS, Fisher LD, Alger KW, Zeronian SH. Physical properties of polyester fibers degraded by aminolysis and by alkalin hydrolysis. J Appl Polym Sci 1982;27:248-57.

[3] Sanders EM, Zeronian SH. An analysis of the moisture-related properties of hydrolyzed polyester. J Appl Polym Sci 1982;27:4477-91.

[4] Datye KV, Palan BH. Effect of alkali on filaments of poly(ethylene terephthalate) and its copolyesters. J Appl Polym Sci 1989;38:1447-68.

[5] Zeronian SH, Collins MJ. Surface modification of polyester by alkaline treatments. Text Prog 1989;20:1-34.

[6] Haghighatkish M, Yousefi M. Alkaline hydrolysis of polyester fibers. Structural effects. Iranian J Polym Sci Technol 1992;1:56-61.

[7] Guebitz GM, Cavaco-Paulo A. Enzymes go big: surface hydrolysis and functionalisation of synthetic polymers. Trends Biotechnol 2008;26:32-8.

[8] Nierstrasz VA. Chapter 7: enzymatic surface modification of textiles. In: Wei Q editor. Surface modification of textiles. Cambridge: Woodhead Publishing Ltd.; August 2009 [ISBN 184569419 8].

[9] Tokiwa Y, Suzuki T. Hydrolysis of polyesters by lipases. Nature 1977; 270:76-8.

[10] Müller RJ, Kleeberg I, Deckwer WD. Biodegradation of polyesters containing aromatic constituents. J Biotechnol 2001;86:87-95.

[11] Alisch-Mark M, Herrmann A, Zimmermann W. Increase of hydrophylicity of polyethylene terephthalate fibres by hydrolases from Thermomonospora fusca and Fusarium solani f. sp. pisi. Biotechnol Lett 2006;28:681-5.

[12] Eberl A, Heumann S, Kotek R, Kaufmann F, Mitsche S, Cavaco-Paulo A, et al. Enzymatic hydrolysis of PTT polymers and olygomers. J Biotechnol 2008; 135:45-51.

[13] Ronkvist AM, Lu W, Feder D, Gross RA. Cutinase-catalyzed deacetylation of poly(vinyl acetate). Macromolecules 2009;42:6086-97.

[14] Alisch M, Feuerhack A, Muller H, Mensak B, Andreaus J, Zimmermann W. Biocatalytic modification of polyethylene terephthalate fibres by esterass from Actinomycete isolates. Biocat Biotrans 2004;22:347-51.

[15] Müller RJ. Biological degradation of synthetic polyesters. Enzymes as potential catalysts for polyester recycling. Process Biochem 2006;41:2124-8.

[16] Nimchua T, Punnapayak H, Zimmermann W. Comparison of the hydrolysis of polyethylene terephthalate fibers by a hydrolase from Fusarium oxysporum LCH I and Fusarium solani f. sp. pisi. Biotechnol J 2007;2:361-4. 
[17] Liebminger S, Eberl A, Sousa F, Heumann S, Fischer-Colbrie G, Cavaco-Paulo A, et al. Hydrolysis of PET and bis-(benzoyloxyethyl) terephthalate with a new polyesterase from Penicillium citrinum. Biocat Biotrans 2007;25:171-7.

[18] Araújo R, Silva C, O’Neill A, Micaelo N, Guebitz GM, Soares CM, et al. Tailoring cutinase activity towards polyethylene terephthalate and polyamide 6,6 fibres. J Biotechnol 2007;128:849-57.

[19] O'Neill A, Araújo R, Casal M, Guebitz GM, Cavaco-Paulo A. Effect of the agitation on the adsorption and hydrolytic efficiency of cutinases on polyethylene terephthalate fibres. Enzyme Microb Technol 2007;40:1801-5.

[20] Herzog K, Müller RJ, Deckwer WD. Mechanism and kinetics of the enzymatic hydrolysis of polyester nanoparticles by lipases. Polym Degrad Stab 2006;91:2486-98.

[21] Müller RJ, Schrader H, Profe J, Dresler K, Deckwer WD. Enzymatic degradation of poly(ethylene terephthalate): rapid hydrolyse using a hydrolase from T. fusca. Macromol Rapid Commun 2005;26:1400-5.

[22] Vertommen MAME, Nierstrasz VA, van der Veer M, Warmoeskerken MMCG. Enzymatic surface modification of poly(ethylene terephthalate). J Biotechnol 2005; $120: 376-86$.

[23] Brueckner T, Eberl A, Heumann S, Rabe M, Guebitz GM. Enzymatic and chemical hydrolysis of poly(ethylene terephthalate) fabrics. J Polym Sci Part A: Polym Chem 2008;46:6435-43.

[24] Donelli I, Taddei P, Smet PF, Poelman D, Nierstrasz VA, Freddi G. Enzymatic surface modification and functionalisation of PET. A water contact angle, FTIR, and fluorescence spectroscopy study. Biotechnol Bioeng 2009;103:845-56.

[25] Štokr J, Schneider B, Doskočilová D, Lövy J, Sedláček P. conformational structure of poly(ethylene terephthalate). Infra-red, raman and N.M.R. spectra. Polymer 1982;23:714-21.

[26] Cole KC, Guevremont J, Ajji A, Dumoulin MM. Characterization of surface orientation in poly(ethylene terephthalate) by front-surface reflection infrared spectroscopy. Appl Spectrosc 1994:48:1513-21.

[27] Liang CY, Krimm S. Infrared spectra of high polymers: Part IX. polyethylene terephthalate. J Mol Spectrosc 1959;3:554-74.
[28] Bahl SK, Cornell DD, Boerio FJ. Interpretation of the vibrational spectra of poly (ethylene terephthalate). J Polym Sci Polym Lett 1974;12:13-9.

[29] Boerio FJ, Bahl SK, McGraw GEJ. Vibrational analysis of polyethylene terephthalate and its deuterated derivatives. J Polym Sci Polym Phys Ed 1976;14:1029-46.

[30] Ward IM, Wilding MA. Infra-red and Raman spectra of poly $(m$-methylene terephthalate) polymers. Polymer 1977;18:327-35.

[31] Walls DJ. Application of ATR-IR to the analysis of surface structure and orientation in uniaxially drawn poly(ethyleneterephthalate). Appl Spectrosc 1991;45:1193-8.

[32] D’Esposito L, Koenig JL. Application of Fourier transform infrared spectroscopy to the study of semicrystalline polymers: poly(ethylene terephthalate). J Polym Sci Polym Phys Ed 1976;14:1731-41.

[33] Holland BJ, Hay JN. The thermal degradation of PET and analogous polyesters measured by thermal analysis-Fourier transform infrared spectroscopy. Polymer 2002;43:1835-47.

[34] Dunn DS, Ouderkirk AJ. Chemical and physical properties of laser-modified polymers. Macromolecules 1990;23:770-4.

[35] Liu C, Jin Y, Zhu Z, Sun Y, Hou M, Wang Z, et al. Molecular conformation changes of PET films under high-energy Ar ion bombardment. Nucl Instrum Methods Phys Res B 2000;169:72-7.

[36] Krimm S. Infrared spectra of high polymers. Adv Polym Sci 1960;2:51-80.

[37] Dadsetan M, Mirzadeh $\mathrm{H}$, Sharifi N. Effect of $\mathrm{CO}_{2}$ laser radiation on the surface properties of polyethylene terephthalate. Radiat Phys Chem 1999;56: 597-604.

[38] Yang X, Long F, Shen D, Qian R. Infra-red determination of conformers of poly (ethylene terephthalate). Polym Commun 1991;32:125-8.

[39] Sun N, Yang J, Shen D. The effect of water on the physical ageing of amorphous poly(ethylene terephthalate) film. Polym Commun 1999;40:6619-22.

[40] Caparanga AR, Basilia BA, Dagbay KB, Salvacion JWL. Factors affecting degradation of polyethylene terephthalate (PET) during pre-flotation conditioning. Waste Manage 2009;29:2425-8. 